\title{
Limitations of Dominance and Forward Induction: Experimental Evidence
}

\author{
Jordi Brandts \\ Instituto de Análisis Económico (CSIC), Barcelona, Spain \\ Charles A. Holt \\ University of Virginia, Charlottesville VA, USA
}

January, 1994

Forward induction implies that foregoing a sure "outside option" can alter subsequent beliefs and behavior. Our laboratory results do not support forward induction, except in a very simple game where it is equivalent to the elimination of dominated strategies.

JEL C72

\section{Introduction}

There are many strategic situations in which early actions by some economic agents may affect decisions taken later by others. For example, consider a firm that gives up an established profit opportunity in one market in order to enter another market in which a second firm is already present. The game shown on the left side of figure 1 provides a simplified representation of this situation. The payoff pair for this game is listed in the top row of each cell, and the payoff for the row player is listed first. The sure profit opportunity, which corresponds to decision $\mathrm{X}$ for the column player, yields payoffs of 55 for both. The column player can enter

Correspondence to: Jordi Brandts, Instituto de Análisis Económico (CSIC), Campus Universidad Autónoma de Barcelona, 08193 Bellaterra, Barcelona, Spain.

Financial support was provided by the Spanish DGCICYT (PB 90-0132 and PB92-0593) and the US National Science Foundation (SES-9012694). 


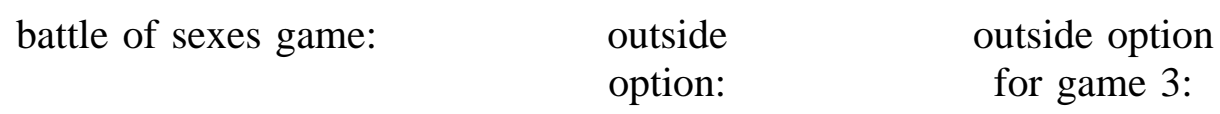

\begin{tabular}{|c|c|c|c|c|c|c|c|}
\hline & & $\mathrm{C} 1$ & $\mathrm{C} 2$ & $X$ & & $\mathrm{C} 1{ }^{\prime}$ & $\mathrm{C} 2$ ' \\
\hline \multirow{2}{*}{$\begin{array}{l}\text { row } \\
\text { player's } \\
\text { actions }\end{array}$} & $\begin{array}{c}\mathrm{R} \\
1\end{array}$ & $\begin{array}{r}40,40 \\
(65,65)\end{array}$ & $\begin{array}{c}50,75 \\
(25,85)\end{array}$ & $\begin{array}{c}55,55 \\
(55,55)\end{array}$ & $\mathrm{R} 1{ }^{\prime}$ & 55,55 & 5,25 \\
\hline & $\begin{array}{l}\mathrm{R} \\
2\end{array}$ & $\begin{array}{c}75,50 \\
(85,25)\end{array}$ & $\begin{array}{l}15,15 \\
(5,5)\end{array}$ & & R2' & 25,5 & 35,35 \\
\hline
\end{tabular}

Fig. 1. Games 1-3.

into the second market with either a low advertising budget, $\mathrm{C} 1$, or a high advertising budget, C2. The row player also chooses between low advertising, R1, and high advertising, R2. The interaction in the second market has the structure of a battle-of-the-sexes game, where each player prefers the outcome where it has high advertising and the other player has low advertising. Although the profit opportunities in the second market are symmetric, the "outside option" may provide a strategic advantage to the column player. Row should understand that column would not give up 55 unless he expected to earn more, and therefore, row should anticipate decision C2 after the outside option is rejected. Column prefers the (R1/C2) outcome that results in payoffs of $(50,75)$, and this outcome is a sequential equilibrium of the game with the outside option.

There is, however, another sequential equilibrium outcome in which column chooses the outside option $\mathrm{X}$, based on the belief that the row player will choose R2 if given the chance. This equilibrium is also sequential, since the beliefs that R2 will be selected are off of the equilibrium path, and hence, not contradicted by actual play of the game. The previously given argument that rules out this outcome is known as "forward induction", since an initial decision affects subsequent beliefs. This paper uses laboratory experiments to evaluate the validity of forward induction. 


\section{Procedures}

Subjects were recruited from classes at the Autonomous University of Barcelona. Six sessions were conducted, each with eight participants and three parts. Part I consisted of four periods in which anonymously paired subjects made independent decisions in the "battle-of-thesexes" game obtained by removing the outside option, except as noted below. The outside option was added to the game used in the four periods of parts II and III, with role reversal in part III. Each period in the final two parts began with the column players making their decisions. Each row player was then told whether the column player with whom they were matched had chosen $\mathrm{X}$ or not, and in the later case the row player had to choose between R1 and R2, without knowing whether $\mathrm{C} 1$ or $\mathrm{C} 2$ had been chosen. ${ }^{1}$ In an effort to induce risk neutrality, the payoffs in figure 1 were in "points"; a subject earned 150 pesetas if the throw of two 10-sided dice at the end of the period was less than the number of points earned. All subjects were matched with a different anonymous partner at the beginning of each period.

\section{Results}

Part I of experiment 1 used the battle-of-the-sexes game on the far left side of figure 1, with payoffs given in the top row of each cell. Equal payoff sums $(40+50=75+15)$ imply that the symmetric mixed-strategy equilibrium is to use probabilities of $1 / 2$, yielding about $25 \%$ of the outcomes in each cell. The top row of table 1 summarizes results that are roughly consistent with this prediction; the difference is not significant at a $10 \%$ level using a chi-square test. The outside option was introduced in part II. When this outside option was rejected, the outcome percentages for the R1/C2 cell (conditional on rejection) rose sharply, reaching 91\% in part III. We conclude that the addition of an outside option has a clear effect on behavior in experiment 1, as predicted by forward induction. Although the outside option is not always rejected, the $\mathrm{X}$ column in table 1 indicates that the tendency to accept it declines between parts

1 Letting column players make their decisions first is consistent with the implicit "message" that Kohlberg and Mertens (1986, p. 1013) use to motivate forward induction: "Look, I had the opportunity to get ... for sure and nevertheless I decided to play this subgame and my move is already made. And we both know that you can no longer talk to me because we are in the game. So think now well and make your decision." 
II and III.

Table 1. Experiment Results.

\begin{tabular}{|c|c|c|c|c|c|}
\hline & \multicolumn{3}{|c|}{$\begin{array}{l}\text { outcome } \% \\
\text { if outside option is rejected }\end{array}$} & \multirow{2}{*}{$\begin{array}{l}\text { outside option } \\
\text { as } \% \text { of total } \\
\text { X }\end{array}$} & \multirow[t]{2}{*}{$\begin{array}{c}\text { number of } \\
\text { observations }\end{array}$} \\
\hline & $\mathrm{R} 1 / \mathrm{C} 2$ & $\mathrm{R} 2 / \mathrm{C} 1$ & other & & \\
\hline experiment 1 , part I & 31 & 17 & 52 & $a$ & 48 \\
\hline experiment 1 , part II & 69 & 0 & 31 & 46 & 48 \\
\hline experiment 1 , part III & 91 & 0 & 9 & 31 & 48 \\
\hline experiment 2 , part I & 19 & 19 & 63 & a & 32 \\
\hline experiment 2 , part II & 29 & 19 & 52 & 34 & 32 \\
\hline experiment 2 , part III & 23 & 8 & 69 & 59 & 32 \\
\hline experiment 3 , part I & 25 & 13 & 63 & a & $8^{\mathrm{b}}$ \\
\hline experiment 3, part II & 11 & 11 & 78 & 44 & 16 \\
\hline experiment 3 , part III & 13 & 0 & 88 & 50 & 16 \\
\hline
\end{tabular}

${ }^{\text {a }}$ No outside option was present.

b There are only 8 observations for the battle-of-the-sexes game since the coordination game on the right side of figure 1 was used for two of the four periods in Part I.

An alternative explanation of the results for experiment 1 is based on the fact that the outside-option payoff of 55 dominates the payoffs of either 40 or 50 that column could get from choosing $\mathrm{C} 1$. Reasoning in this manner, dominance also predicts the R1/C2 outcome. To design an experiment that distinguishes between dominance and forward induction, we will use a more precise definition of forward induction due to van Damme $(1989,485)$ : "...in generic two-person games in which player $i$ chooses between an outside option or to play a game $\Gamma$ of which a unique viable equilibrium $e^{*}$ yields this player more than the outside option, only the outcome in which $i$ chooses $\Gamma$ and $e^{*}$ is played ... is plausible." Experiment 2 used the battle-of-the-sexes game on the left side of figure 1, with an outside option $\mathrm{X}$ and with payoffs given in the bottom 
row of each cell. Note that neither C1 nor C2 are dominated by the outside option payoff of 55, but forward induction, as defined above, selects the R1/C2 outcome. ${ }^{2}$ Part I of this experiment used the battle-of-the-sexes game by itself. In contrast to experiment 1 , the addition of the outside option does not lead to a predominance of the forward induction prediction (R1/C2). The increase in experience even leads to increased reliance on the outside option X, up from $34 \%$ in part II to $59 \%$ in part III.

Experiment 3 used game 1 payoffs from the left side of figure 1, with the sure outside option $\mathrm{X}$ being replaced by a coordination game, shown on the right side of figure 1 . The absence of a sure outside option precludes the application of forward induction, as defined above. However, a straightforward iterated dominance argument selects R1/C2 as the unique outcome; first eliminate $\mathrm{C} 2$ ', which is dominated by $\mathrm{C} 1$, then eliminate the now dominated $\mathrm{R} 2$ ', and one obtains game 1. The data for experiment 3 show that the addition of the coordination game in parts II and III does not increase the frequency of (R1/C2), but actually decreases it, in contrast to the prediction of iterated dominance. Moreover, table 1 shows a substantial use of $\mathrm{C} 1$ ' and C2' (44 and 50\%), which is ruled out by iterated dominance.

\section{Conclusion}

Our results and those of Cooper et al. (1993) cast some doubt on the usefulness of forward induction. ${ }^{3}$ In particular, Cooper et al. (1993) show that behavior is dramatically affected by the focal asymmetry created by the outside option, even if the payoffs resulting from this option are so low that forward induction does not apply. In this paper, we document another sense in which forward induction is of limited use; it works fairly well in game 1 where it coincides with a simple dominance argument, but it fails in game 2 where dominance does not

2 Since column chooses between $\mathrm{C} 1, \mathrm{C} 2$ and $\mathrm{X}$ in the first stage, the battle-of-the-sexes is not a proper subgame of game 2. The fact that column has already moved when row chooses an action makes our set-up more favorable to forward induction than a design in which the battle-of-the-sexes is a proper subgame (cf. the Kohlberg and Mertens quote in footnote 1).

3 Cooper et al. (1992) have shown that forward induction can have a major effect in experiments involving a choice between a sure outside option and a coordination game, with two Pareto-ranked equilibria. 
apply. The failure of forward induction in game 2 is notable since the focal asymmetry of the outside option was the same as in game 1. The results of game 3 show that even iterated dominance arguments may not work in relatively simple situations. In Brandts and Holt (1992 and 1993), we argue that an analysis of the process of learning and adjustment can be more useful than deductive "refinements" used to select among multiple equilibria.

\section{References}

Brandts, J. and C.A. Holt, 1992, An experimental test of Nash refinements in signaling games, American Economic Review 82, 1350-1365.

Brandts, J. and C.A. Holt, 1993, Adjustment patterns and equilibrium selection in experimental signalling games, International Journal of Game Theory 22, 279-302.

Cooper, R., D.V. DeJong, R. Forsythe, T. W. Ross, 1992, Forward induction in coordination games, Economics Letters 40, 167-172.

Cooper, R., D.V. DeJong, R. Forsythe, T. W. Ross, 1993, Forward induction in the battle-of-thesexes games, American Economic Review 83, 1303-1316.

Kohlberg, E. and J. Mertens, 1986, On the strategic stability of equilibria, Econometrica 54, 1003-1038.

van Damme, E., 1989, Stable equilibria and forward induction, Journal of Economic Theory 48, 476-496. 